\title{
A Non-Accident-Based Spatial Method to Analyse Pedestrian-Vehicular Conflict
}

\author{
Lakshika Meetiyagoda \\ Department of Town \& Country Planning, University of Moratuwa, Sri Lanka \\ Email: meetitlm@uom.lk
}

\begin{abstract}
Due to the tremendous increase in automobile transportation and heavy pedestrian movements in developing countries, roads are becoming deadlier year by year. It is acknowledged that context specific research on pedestrian-vehicular conflict are urgently needed considering the built environment characteristics. Therefore, this paper aims to (1) redefine pedestrian-vehicular conflict that would enable to explain micro- and macro-built environment-related variables in a particular context, and (2) develop a methodology that could be used in a place where comprehensive data are limitedly available for a spatial analysis. This research redefines pedestrian-vehicular conflict as "the pedestrian contact with potentially harmful vehicular traffic", rather than accidents. Based on this definition devise a methodology. The primary data collection method adopted to collect causal factors related to spatial data was, photographs. The spatial data were analysed by using QGIS platform. The pedestrian volume models are constructed by a space syntax framework and correlated with a composite choropleth map to get the potential conflicting points. A perception survey was carried out to confirm the spatial analysis. The research findings indicate that the methodology developed can be used to identify built environment factors related risk areas spatially. Consequently, it is possible to fill the research gap by introducing a low-cost, widely applicable, impartial, spatial and perception-based methodology that assesses the built environmental characteristics in relation to pedestrian-vehicular conflict. This research would support the urban planners and designers, allowing them to comprehend the risk related nature of pedestrian-vehicular conflict in their urban planning schemes before intervening with plans and designs.
\end{abstract}

(C) 2019 Penerbit UTM Press. All rights reserved

\author{
Article History \\ Received : 15 January 2019 \\ Received in revised form : 24 March 2019 \\ Accepted : 17 April 2019 \\ Published Online : 30 April 2019

\section{Keywords:} \\ Accidents; built environment; spatial analysis; \\ space syntax; photographs
}

\section{Corresponding Author Contact:}

meetitlm@uom.lk

DOI: $10.11113 /$ ijbes.v6.n2.341

\section{Introduction}

People in developing countries such as India and Sri Lanka are from diverse backgrounds and adhere to different living standards. The traffic characteristics and the road designs are also quite distinctive when compared to some developed countries such as the Netherlands, Portugal and Hong Kong (Kadali, Rathi and Perumal 2014 and Meetiyagoda 2018). Thus, road users, particularly pedestrians, invariably come across difficulties such as pedestrian-vehicular conflicts due to lack of proper planning solutions. Presently, the traffic engineers design the road space, including the pedestrian domain, and urban planners and designers plan for land uses and built form characteristics. Many research studies on spatial planning and design interventions have focused on the pedestrian-vehicular conflicts. Some scholars note the way of separating pedestrians 
from automobiles (Hajdu 1988; Robertson 1993; Khder, Mousavi and Khan 2016), and some others discuss the way of sharing the street space by prioritising the pedestrian (BenJoseph 1995; Hamilton-Baillie 2008; Khan et al. 2015). Some recent studies suggest augmenting the public transportation facilities (Zaman et al. 2017). However, the prevailing conceptualisations of the pedestrian-vehicular conflict, evaluation methods and solutions are also mostly devised by traffic engineers (Ranasinghe et al. 2015). They mainly consider macro-variables such as capacity, demand, volume, rate of flow, trip origin/destination analysis, congestion patterns, and regional land use patterns, while urban planners and designers need to focus on both macro- and micro-variables, including built environment and local land uses and form (Southworth 2005). Meanwhile, the land use planning efforts need to fulfil the requirements of pedestrians to ensure safe and comfortable pedestrian access (Kadali, Rathi and Perumal 2014). It is a complex task for policy-makers, planners and designers to make a snug, convenient and safe pedestrian domain, which is compatible with existing land uses and contextual characteristics. Therefore, there is a research gap to redefine and analyse pedestrian-vehicular conflict in relation to the builtenvironmental factors.

Moreover, the cities claiming some heritage values, especially, face constraints in executing the necessary expansions. As different user groups demand different services, urban planners and designers need to put more effort into comprehending the micro situations and proposing solutions. Steinmetz (2004) recommends strong observation-based empirical research when a phenomenon manifests to a particular context.

In this background, it is necessary to review the literature, define the phenomenon, discover the causal factors and test their availability in a case study and to determine the other causes that exist outside the theory. Therefore, this paper considers pedestrian-vehicular conflict in a heritage city by redefining it with non-accident and built environment- based causal factors and by introducing a low-cost, impartial method to spatially analyse the phenomenon.

\section{Prior Studies}

A number of research studies have explored pedestrianvehicular collision/crashes/conflicts. However, most of the studies either get accident data from police reports and analysis the nature of the crash, but limitedly discuss the causes of conflict risks (Black and Westerman 1989). Meanwhile, few studies incorporated spatial data and perception data (Braddock et al. 1994; Schuurman et al. 2009; Lerman, Rofe and Omer 2014).

In 1980s, Black and Westerman (1989) suggest a framework to collect the data based on the factors influencing road safety. Their intention is to derive a low-cost and practical process, which identifies the significant variables within the context of the road function and the road environment. The data collection methods include video recordings, observations and perception survey. The main analysis methods which they used were correlation analysis and video analysis. However, they mention that the occurrence of accidents is difficult to observe in practice, and historical data reconstruction is only partially possible when information on the accident is incomplete. Moreover, though they suggest a correlation analysis, in general, the number of accidents are often too small to establish statistically significant correlations. Their suggestion is to study of the traffic behaviour as an alternative approach.

In 1990s, Braddock et al. (1994) demonstrate the effectiveness of Geographical Information System (GIS) when examining the child pedestrian conflict by using a 20-year motor vehicle collision records from the Police Department. They used TransCad to code the location of the collision by address matching and develop point maps. This analysis enables them to recognise the distribution pattern of collision within the city, and it proves the ability of using GIS to illustrate the spatial relationship between conflict and other land uses. However, this research focuses more on the characteristics of collision than causes. At the same time, the authors accept the fact that police accident records underestimate the occurrence of non-roadway pedestrian collisions. Nevertheless, this study recommends sitespecific interventions to prevent the collisions. The authors' future research intention is investigation of other geographical features.

In 2000s, Schneider, Ryznar and Khattak (2004) conducted the crash analysis by incorporating perceived risk data and the crash records from the police reports. The spatial analysis was also based on GIS. This analysis was combined with regression analysis to understand the factors associated with risk. As a result of spatial analysis, the study identified crash clusters and the density of clusters by using kernel estimation method. Moreover, they produced another map with pedestrian perception. When comparing the two types of data sources, it shows a difference between the locations of police-reported crashes and the places where people perceived as having a potential of a crash. Thus, this research study encourages scholars to research on perceived pedestrian risks over police reported crash. However, they recommend to use their methodology only for moderately perceived crash-risk areas like campuses, neighbourhoods and commercial areas.

Moreover, Parks and Schofer (2006) tested the ability of using secondary data in ArcGIS platform and digital aerial photographs to measure the quality of the pedestrian environment. Then, linear regression was used to estimate and derive several models. The result of the research proves the ability of using laboratory collected variables to assess proposed pedestrian environment design.

Raford and Ragland (2003) explore the possibility of incorporating space syntax volume-modelling approach for estimating pedestrian volume. The urban street network has analysed with space syntax model to generate "movement potentials", and at the same time sample pedestrian counts were collected from key locations. At the end they compare this pedestrian-risk analysis with the crash data. The authors 
conclude that spatial syntax model has a detailed level of prediction capacity and it is not a complex model. However, they acknowledged the requirement of integrating automobile volume and land use characteristics.

\subsection{Gap In The Literature}

According to previous literature, it reveals that many studies (a) depend on police accident reports; (b) aim to find the characteristics of crash/conflict; (c) do not study in detail how built environmental characteristics causal to crash risks and the perception of pedestrians on such characteristic; or (d) use data collected by sophistic methods. Redefining pedestrian-vehicular conflict is again an important consideration in this respect.

Therefore, this study attempts to fill some of these gaps by collecting site specific data on built environmental characteristics with the use of streetscape photographs so as to data would be up-to-date and involve less expensive. It will analyse the potential risks by utilising GIS based spatial analysis. Subsequently, spatial analysis is verified with pedestrian perception. Another importance of this method is that it educates pedestrian and drivers about the areas with perceived risks to get some precautions to prevent injuries and fatalities.

\section{Redefining Pedestrian-Vehicular Conflict}

The broader concept of pedestrian safety can be replaced with the systematised concept of pedestrian-vehicular conflict, as there are ample scholarly works discussing why and how the pedestrian-vehicular conflict affects pedestrian safety (Stoker, Adkins and Ewing 2017; Cloutier et al 2017; Osama and Sayed 2017).

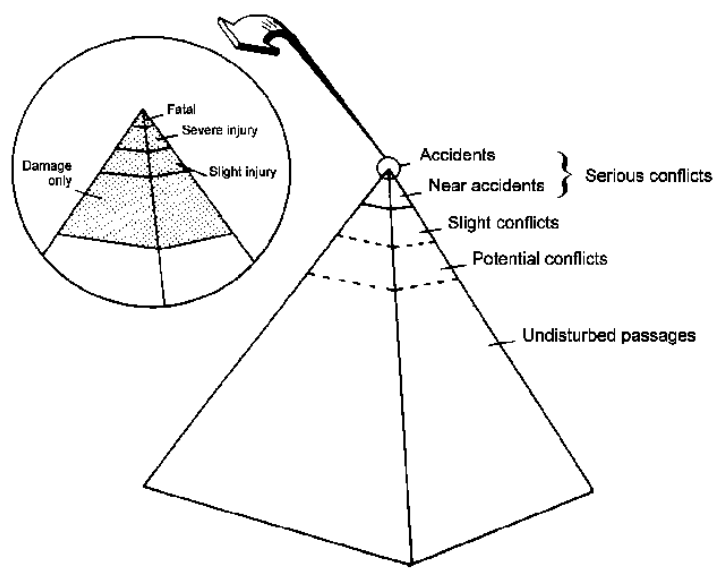

Figure 1 Safety pyramid (Hydén, 1987)

Hydén (1987) illustrates in his seminal research project that accident records are not an ideal representation or evaluation criterion of pedestrian safety. The safety-related interaction between different road users is described using a number of elementary events, and the conceptualisation is presented by the 'safety pyramid' (Figure 1). Hydén's hypothesis postulates that when there is pedestrian and vehicle conflict, the seriousness of conflict indicates the disintegration between two road users. He says pre-crash phases of the safety pyramid can be observed by comparing them to the nature of accidents and allowing for people to study the process causing the accidents.

Raford and Ragland (2003) define pedestrian-vehicular conflict as "pedestrian contact with a potentially harmful vehicular traffic", and "the probability that a pedestrian-vehicle collision will occur" is defined by them as pedestrian-risk. Thus, this research rests on Raford and Ragland's definition as its working definition. By following this concept, 22 causal factors associated with the built environment, vehicular and pedestrians are identified in the light of literature review. See Figure 2 below:

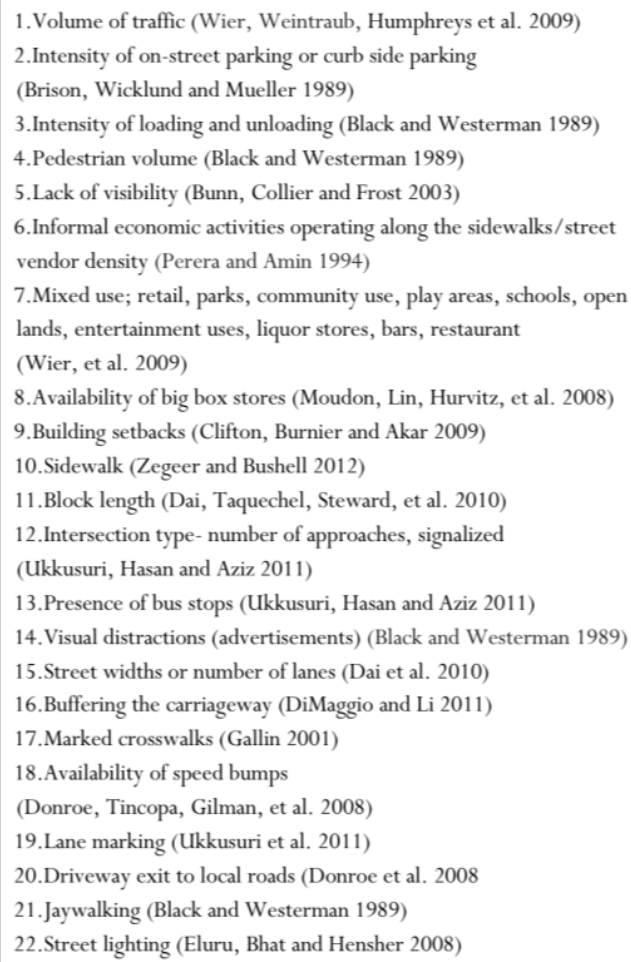

Figure 2 Causal factors identified in light of the literature (Author)

\section{Devising a Methodology}

This research can be described as an explanatory or causal inference-based research, which expounds its findings by exploring a single empirical case study (i.e., The Kandy Heritage City) (Figure 3) that manifests a single phenomenon, i.e., pedestrian-vehicular conflict (Gerring 2004 and Swanborn 2010). 


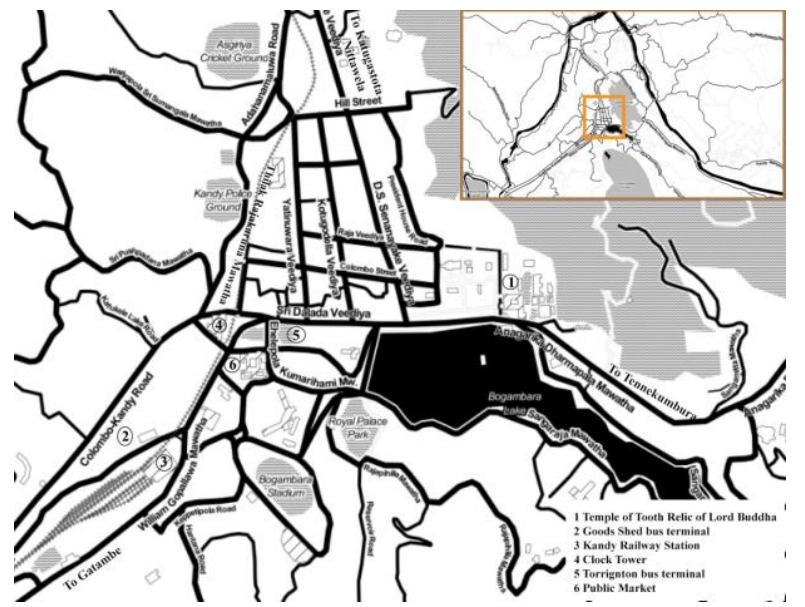

Figure 3 A base map of Kandy (Author)

\subsection{Shortlisting of the Causal Factors according to the Context}

A pedestrian's perception survey was conducted in the Kandy Heritage City to shortlist the causal factors. A structured questionnaire was distributed among thirty (30) randomly selected local and foreign pedestrians. First, they were asked to indicate their level of satisfaction with the pedestrian environment in terms of safety. If not satisfied with the present situation, they were asked to prioritise the literarily identified causes to understand the reasons behind their views. Apart from the perception survey, general public discourse and observation assisted the short-listing of the seven casual factors, namely, people on carriageways, land use, undefined pedestrian domain, intersection type, on-street parking, constrained or no sidewalk space and loading and unloading, which cause pedestrianvehicular conflict to be embedded in the Kandy Heritage City.

Meanwhile, it may be noted that together with factors such the road network layout, connectivity and spatial integration, scholars have already identified the capacity of a space syntax modelling tool for analysing the potential pedestrian volume (Raford and Ragland 2004; Omer and Kaplan 2017). Baran, Rodríguez and Khattak (2008) mention that movement patterns between the different spaces of the built environment are viewed by space syntax as a system and assume better physical connections (the ability to reach from a particular point to every other point), fewer turns and a longer line of sights tend to generate a higher density of movements. Therefore, this research considers spatial integration, which is derived from space syntax analysis, to be a promising predictor of pedestrian movement patterns.

\subsection{Data Sourcing}

Three main sources of information were used in this research, namely, photographs, GIS data of the road network and pedestrian perception. First, photographs were used to evaluate the spatial variation of seven causal factors. A review of the literature shows that different scholars have included photographic surveys to record the pedestrian and vehicular data at the streetscape level (Sakar and Andreas 2004; Parks and Schofer 2006; Ewing, Handy, Brownson et al. 2006; Sepe 2009). Second, the Kandy Road network shape file of GIS has been used to make the axial map manually and, thereby, to prepare a space syntax map that predicts the pedestrians' movement patterns. Third, a perception survey was used to gather additional information about and interests of the people, which could not have been recorded otherwise with secondary data or photographic survey only. This survey is a common method that cross-checks the computer-based data modelling with people, and it has been used by scholars to identify the conflict behaviour and people's perception (Black and Westerman 1989; Sepe 2009; Dai et al. 2010). Another round of the pedestrian perception survey had to be incorporated after the computer-based analysis to validate the results and particularly to identify the causal factors. It was intended to identify fifty (50) of the highest scored points of the composite choropleth map, and five (5) road users had to be interviewed in respect to each point. Thus, two hundred fifty (250) respondents had to be involved in validating the results.

\subsection{Content Analysis of Photographs}

Photographs were the main source of information in this research. After the streetscape elevation picture frame was made (Figure 4), it had to be subjected to content analysis based on the factors mentioned in the Table 1. Scholars state that still images or photographs represent one form of qualitative data, and content analysis is a widely used qualitative data analysis technique that summarises the information in texts or photographs in smaller categories by coding (Bernard and Ryan 2009; Meetiyagoda and Munasinghe 2009). In this research, directive content analysis was used, as the codes (or variables) were already derived based on the literature and observations (Hsieh and Shannon 2005). During the content analysis, the authors basically read the information that appears on the photo, coded it and described in detail along with statistics. Accordingly, the evaluation had to be done by using the coding scheme, which was derived based on a 1-5 Likert scale (Table 1). The content analysis had to be done for each picture frame representing the street segment of each $25 \mathrm{~m}$ in the Kandy Heritage City (Figure 4), and the codes were fed to the attribute tables of the Quantum Geographical Information System (QGIS) 2.12.1-Lyon and IBM Statistical Package for Social Science (SPSS), version 21 for analysis. This analysis proved the possibility of deriving quantifiable data from it. 


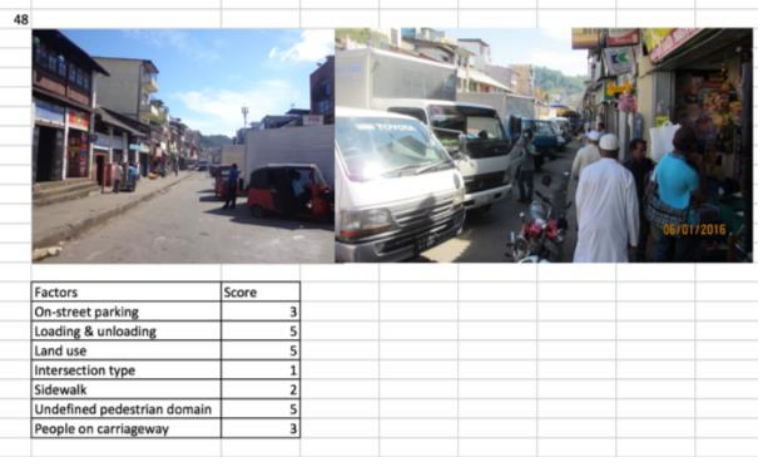

Figure 4 A sample of content analysis of photographs (Author)

\subsection{Visualising Geographic distribution of Causal Factors}

The data obtained from content analysis of the photographs had to be converted to spatial data by using QGIS. Pulugurtha, Krishnakumar and Nambisan (2007) mention that features of GIS have the facilitation capability to identify the high pedestrian crash areas with a lower degree of subjectivity. Thus, by means of this spatial analysis, it is expected to identify the spatial distribution of causal factors related to pedestrian-vehicular conflict in the Kandy Heritage City. Hotspot mapping is a widely used simple analytical technique in QGIS, which enables the identification of locations where accidents, diseases or crimes are clustered (Anderson 2007; Chainey, Tompson and Uhlig 2008). Chainey Tompson and Uhlig (2008) mention that point mapping is straightforward, as it represents each event as a point and helps us to visualise geographic distribution by employing the QGIS functions of thematic shading. Rytkonen (2004) also states choropleth maps are used to display some data as spatial units by colouring, shading or hatching. As pointed out by Crampton (2002), the fundamental principle of choropleth mapping is that "the densities of shading on the map are cognitively parallel to the densities of data". The possibility of displaying different data layers with different highlighted data values is an advantage of choropleth maps. When analysing a map to record the places of pedestrian-vehicular conflict and to geocode and produce a point map, the photographs capturing these locations are needed. Each point was attributed a value from its measurement in the attribute table (Table 1). Then, the point information was converted into a choropleth map, which shows the continuous shades of colours to indicate the performances of different causal factors. According to Tobler (1973), the visual intensity of a choropleth map is exactly proportional to the data value

Table 1 Coding scheme for the content analysis of photographs

Source: Author

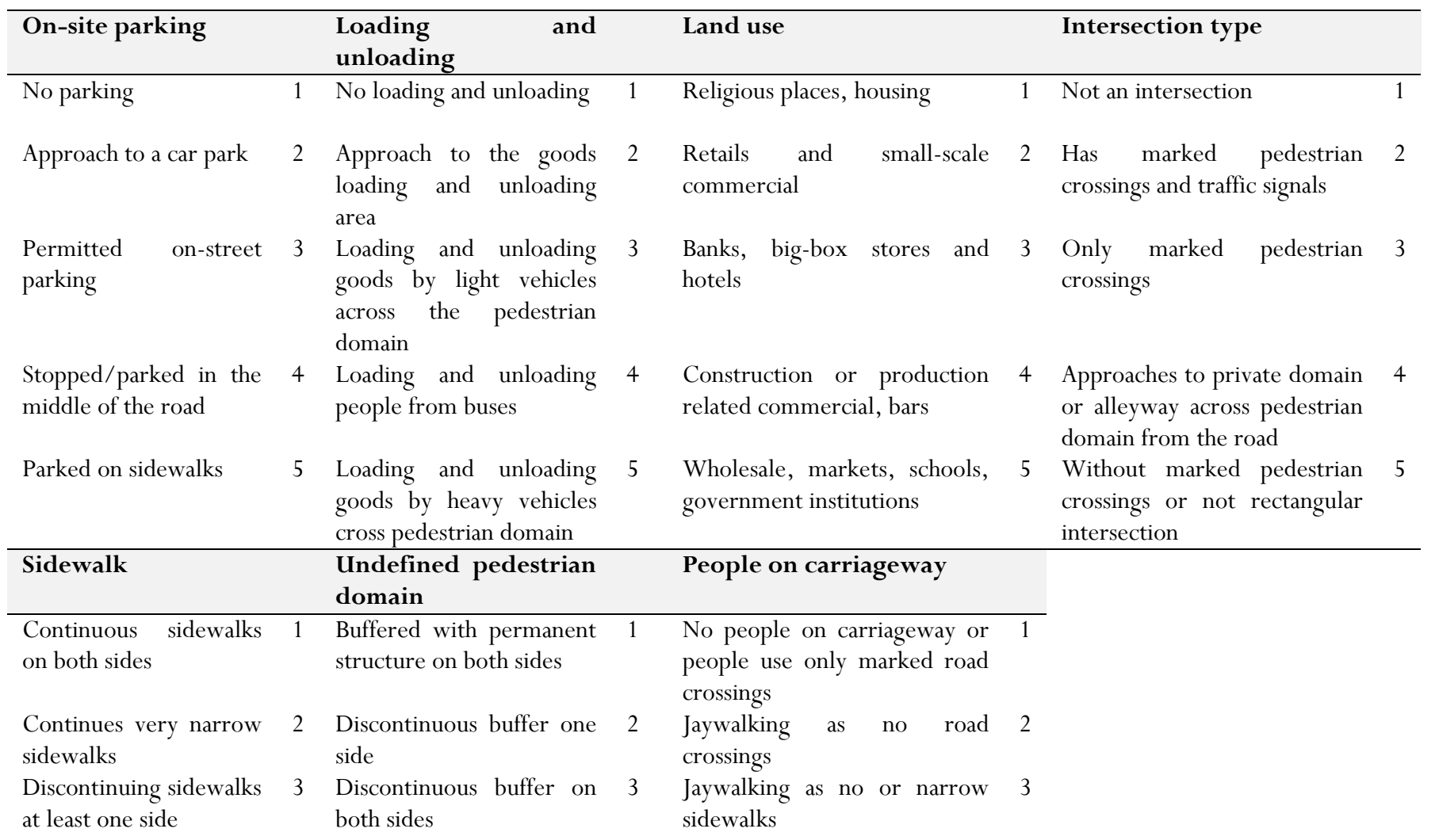




\author{
Width of the sidewalks \\ not enough for \\ pedestrian as it is used \\ for street vending \\ No space provided for \\ sidewalk at least one \\ side
}

\subsection{Space Syntax Analysis}

The aim of space syntax (that is, the language of space) analysis is to quantify and compare the pattern properties of architectural space or the space between buildings in urban areas and building interiors. According to Bandara, Meetiyagoda and Munasinghe (2010), space syntax is gaining popularity in the area of planning and urban design, mainly due to the urban space modelling possibilities demonstrated by the method associated with it.

The first step in space syntax analysis is transcribing the street network into an axial map. An axial map is "a network of intersecting lines that consists of the longest set of lines of sight that passes through the street space" (Kim and Penn 2004). DepthmapX software has been used to produce the axial map with network analysis once the lines are drawn manually in the QGIS platform. The modelling facilitates assigning a value for each axial line in terms of connectivity, control value, local and global integration. The notion of integration should be defined with the notion of 'depth'. Jiang and Claramunt (2002) define depth as "the number of lines distant from a given number of steps to that axial line”. Integration indicates how easily one can reach a specific street or the line of the axial map. When computing access to one line from all the other lines of the axial map, it is called the global integration; if the computed integration value is based on a given number of lines (radii), it is called local integration. The calculation of depth and connectivity is derived from the following equation.

$$
\sum_{s=1}^{m} s \times N_{s}=\left\{\begin{array}{l}
\text { Connectivity iff } m=1 \\
\text { local depth iff } m=k \\
\text { global depth iff } m=l
\end{array}\right\}
$$

$\mathrm{s}=$ shortest distance (or steps) from the node

$\mathrm{Ns}=$ number of nodes within the shortest distance

$l=$ maximum shortest distance

For this research, the global integration has been calculated, as it represented most integrated and demanded areas for pedestrian movements in the Kandy Heritage City as a whole. Global integration is the indicator of the attractiveness of different public spaces in the overall spatial configuration of the city (Bandara and Munasinghe 2007). The Space Syntax Toolkit (plug-in) of QGIS was used to handle the geometric and geographic data associated with attribute information, to perform spatial, mathematical and statistical calculations, and to visualise the results (Gil et al. 2014).
4 Jaywalking as sidewalks are 4 occupied by the vehicles or no sidewalks

5 Informal gathering on street as 5 a result of vehicles parked on sidewalks or no sidewalks

\subsection{Construct Validation with SPSS}

A requisite construct validation was conducted to confirm spatial analysis. First, it confirmed the association between pedestrian volume and causal factors for conflict. For this purpose, correlation analysis was employed in the SPSS platform, and it helped to identify the relationship that exists between each causal factor. At this juncture, global integration values of space syntax analysis were to be benchmarked to enable correlation analysis. For this purpose, a buffer of $25 \mathrm{~m}$ had been defined for each conflicting point and had employed the union tool of QGIS to overlap the space syntax layer with buffered conflicting points. Then, the average integration values were assigned under each conflicting point and benchmarked with reference to a 1-5 Likert scale. The two variables subjected to analysis are treated equally but not as predictors or as an outcome.

The second type of construct validation taken up was pedestrian perception, which was used to validate the potential conflict clusters that were derived by spatial analysis. In the process of this pedestrian perception survey, five randomly selected pedestrians from each selected location (250 respondents) were asked, first whether they agree with the view that the location has a potential conflict, and second, they were asked to prioritise the seven causal factors. The responses were subjected to a simple descriptive analysis, which enabled us to identify the most influential casual factors.

\section{Results of Empirical Study}

\subsection{Results of Spatial Analysis}

A syntactic analysis of spatial integration of the Kandy Heritage City begins by representing the road network with axial lines. The global analysis of space syntax modelling is considered to discuss the results, and according to the level of integration, the colour of axial lines ranges from deep blue to deep red, that is, below the mean integration value to above the mean integration value, respectively. In another words, the axial lines with deep red represent the highest pedestrian volume concentration, which reflects Penn's claim (2003). The highest pedestrian volumes (see Figure 5) are concentrated at the Kandy City Centre, specifically around main transport terminal areas, the public market and the grid city area. However, this finding contradicts what Raford and Ragland's (2003) research (which also used the space syntax analysis to represent pedestrian volume), which reveals that a higher number of pedestrian crashes occurs in the peripheries and not downtown, where the highest number of intersections are concentrated. However, they admit the fact that their findings are contrary to the general research expectations. The average research 
findings elaborate the concentration of pedestrian-vehicular conflict in city centres (Steenberghen, Dufays, Thomas et al. 2004) as is the case with the Kandy Heritage City.

Moreover, the aggregate values of seven causal factors represent the points of the composite choropleth map, which denotes the highest potentials of conflicting points from least possible conflicting points by varying the colours from deep red to light green, respectively. The map indicates that the highest potential conflicting locations are mostly concentrated at the grid city (Figure 6), where the pedestrian volume is also substantially high, according to the space syntax analysis.

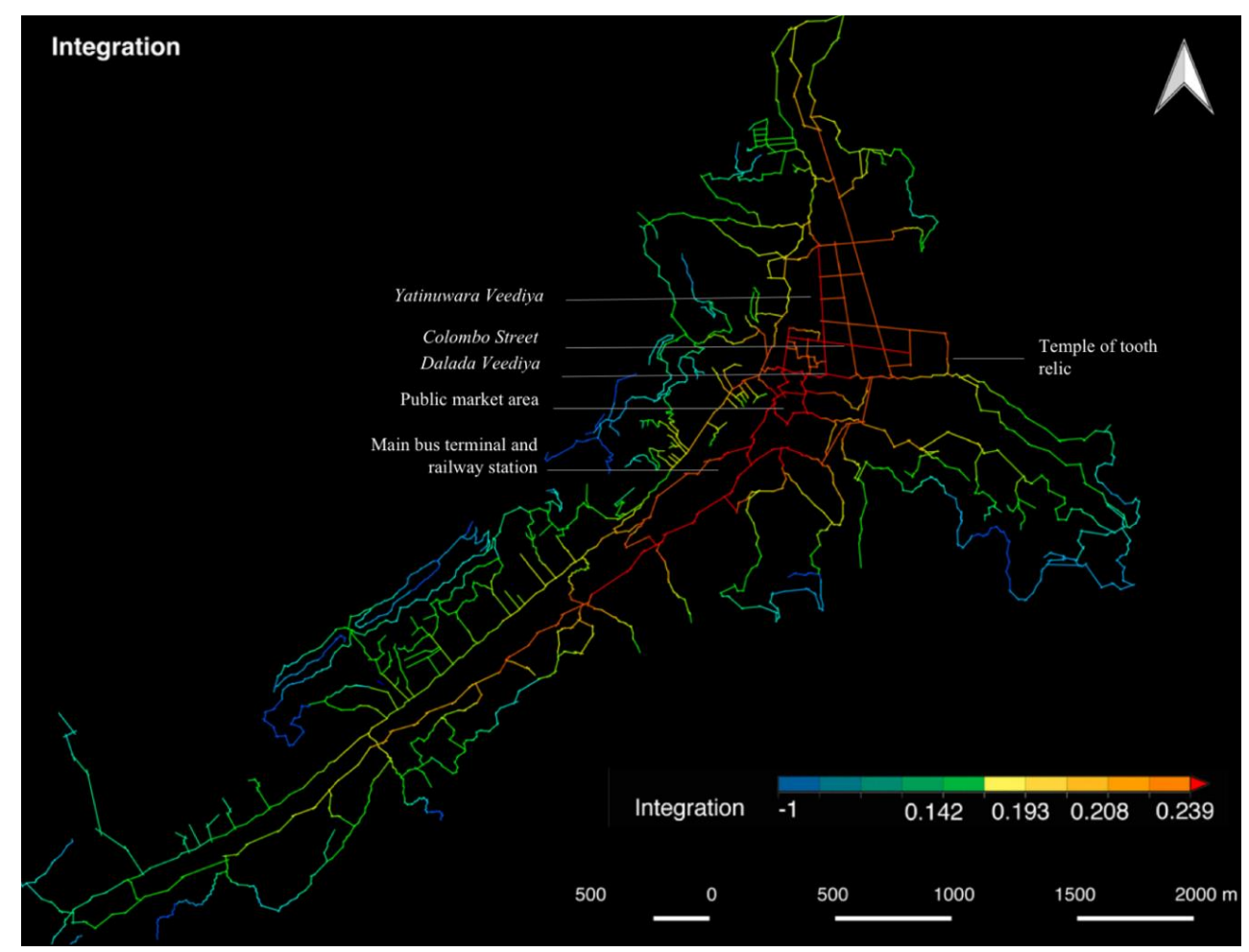

Figure 5 Global spatial integration (Author)

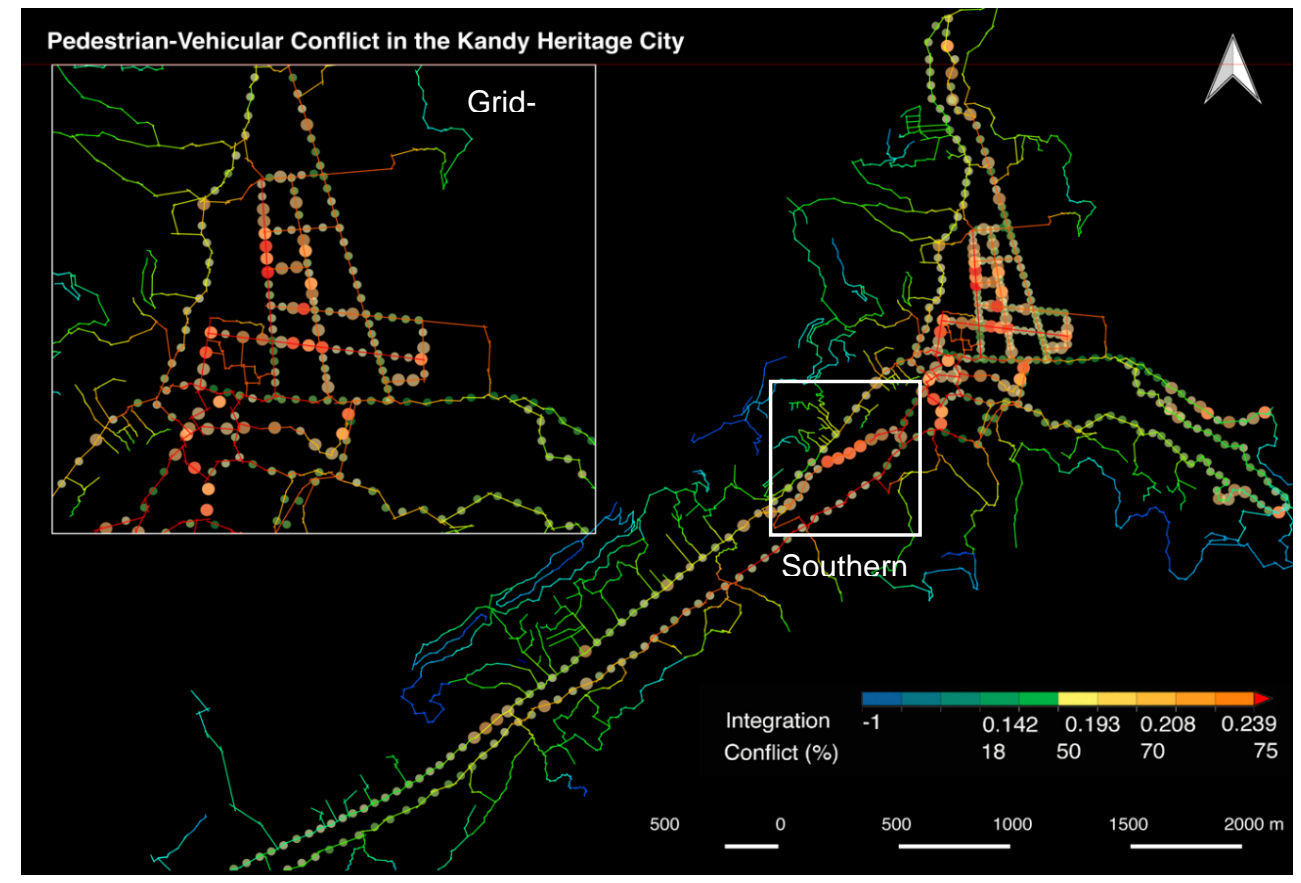

Figure 6 The overall outcome of the analysis: Pedestrian-vehicular conflict of the Kandy Heritage City (Author 


\subsection{Validation}

According to the correlation analysis, which was undertaken to find the relationship between the seven causal factors and integration level, on-street parking, loading and unloading, land use and people on the carriageway are positively and significantly correlated with integration and thereby with the pedestrian volumes (Table 2). However, on-street parking $(\mathrm{r}=$ $0.182, \mathrm{p}=0.000)$, loading and unloading $(\mathrm{r}=0.126, \mathrm{p}=0.010)$, land use $(\mathrm{r}=0.258, \mathrm{p}=0.000)$ and people on carriageway as a result of vehicles $(\mathrm{r}=0.258, \mathrm{p}=0.000)$ indicate weak correlation (less than 0.3) (Acock 2008). The causal factor, undefined pedestrian domain negatively correlates with weak negative $r$ value $(r=-0.201, p=0.000)$, perhaps because planning agencies have recently improved two mostly integrated streets (i.e. Sri Dalada Veediya and Willium Gopallawa Mawatha (Figure 3)) with required pedestrian infrastructure such as fencing. Further, when it was examined the relationship between people on carriage way as a result of vehicles and the other indicators, it was found that it is positive and significant, which indicates that there is a pedestrian-vehicular conflict. People on carriage way as a result of vehicles and on-street parking are the highest correlated items with moderate $r$ value $(\mathrm{r}=0.453, \mathrm{p}=0.000)$, because people might tend to use carriageway to walk when sidewalks are occupied to park vehicles. The reasons of on-street parking can be predicted, considering the correlations of other indicators, namely, loading and unloading $(\mathrm{r}=0.311, \mathrm{p}=0.000)$ land use $(\mathrm{r}=0.258, \mathrm{p}=$ $0.000)$ and undefined pedestrian domain $(r=0.240, p=0.000)$.

As per the pedestrians' perspective of this result, $82 \%$ of the respondents agreed with the identified pedestrian-vehicular conflicting locations. Additionally, according to their perception, the top five factors causing conflict are as follows: undefined pedestrian domain [44\%]; on-street parking [37\%]; land use [35\%]; loading and unloading [30\%] and constrained or no sidewalks [29\%]. Various research findings, as well as pedestrians' perception survey of the Kandy Heritage City, emphasise that these five causal factors are influential in terms of pedestrian-vehicular conflict. Rahaman, Ohmori and Harata (2005) identify a buffer (between sidewalks and carriageways) to be a considerable safety issue. Respondents in their research have also stated that the absence of any definition between the sidewalks and carriageways is a main cause of pedestrianvehicular conflict. Moreover, Brison et al. (1988), Donroe et al. (2008) and Shepherd, Austin and Chambers (2010) found that curb side or on-street parking is a cause of fatal accidents. Loading and unloading is a combined cause, along with land use, and that activity is less common in many heritage cities; thus, it is perceived as a problem by many pedestrians of the Kandy Heritage City. McMahon et al. (2002) found that sidewalks had no effect on pedestrian-vehicular conflict. However, Ossenbruggen, Pendharkar and Ivan (2001) stated the probability of a conflict is about two times more at a site without a sidewalk than a site with a sidewalk.

Table 2 Correlation analysis

\begin{tabular}{|c|c|c|c|c|c|c|c|c|c|}
\hline Causal factors & & $\begin{array}{c}\text { On- } \\
\text { street } \\
\text { parking }\end{array}$ & $\begin{array}{l}\text { Loading } \\
\text { and } \\
\text { unloading }\end{array}$ & $\begin{array}{l}\text { Land } \\
\text { use }\end{array}$ & $\begin{array}{l}\text { Intersection } \\
\text { type }\end{array}$ & $\begin{array}{c}\text { Constrained } \\
\text { or no sidewalk } \\
\text { space }\end{array}$ & $\begin{array}{l}\text { Undefined } \\
\text { pedestrian } \\
\text { domain }\end{array}$ & $\begin{array}{c}\text { People on } \\
\text { carriageway as a } \\
\text { results of } \\
\text { vehicles }\end{array}$ & Integration \\
\hline \multirow{4}{*}{$\begin{array}{l}\text { On-street } \\
\text { parking }\end{array}$} & Pearson & 1 & & & & & & & \\
\hline & Correlation & & & & & & & & \\
\hline & $\begin{array}{l}\text { Sig. } \\
\text { tailed) }\end{array}$ & & & & & & & & \\
\hline & $\mathrm{N}$ & 419 & & & & & & & \\
\hline \multirow{4}{*}{$\begin{array}{l}\text { Loading and } \\
\text { unloading }\end{array}$} & Pearson & $.311^{* *}$ & 1 & & & & & & \\
\hline & Correlation & & & & & & & & \\
\hline & $\begin{array}{l}\text { Sig. } \\
\text { tailed) }\end{array}$ & .000 & & & & & & & \\
\hline & $\mathrm{N}$ & 419 & 419 & & & & & & \\
\hline \multirow[t]{4}{*}{ Land use } & Pearson & $.258^{* *}$ & $.410^{* *}$ & 1 & & & & & \\
\hline & Correlation & & & & & & & & \\
\hline & $\begin{array}{l}\text { Sig. } \\
\text { tailed) }\end{array}$ & .000 & .000 & & & & & & \\
\hline & $\mathrm{N}$ & 419 & 419 & 419 & & & & & \\
\hline \multirow{4}{*}{$\begin{array}{l}\text { Intersection } \\
\text { type }\end{array}$} & Pearson & -.036 & .054 & .064 & 1 & & & & \\
\hline & Correlation & & & & & & & & \\
\hline & $\begin{array}{l}\text { Sig. } \\
\text { tailed) }\end{array}$ & .465 & .269 & .191 & & & & & \\
\hline & $\mathrm{N}$ & 419 & 419 & 419 & 419 & & & & \\
\hline Constrained & Pearson & .094 & -.046 & .045 & .014 & 1 & & & \\
\hline
\end{tabular}

or no sidewalk Correlation 


\begin{tabular}{|c|c|c|c|c|c|c|c|c|c|}
\hline \multirow[t]{2}{*}{ space } & $\begin{array}{l}\text { Sig. } \\
\text { tailed) }\end{array}$ & .053 & .353 & .358 & .772 & & & & \\
\hline & $\mathrm{N}$ & 419 & 419 & 419 & 419 & 419 & & & \\
\hline \multirow{4}{*}{$\begin{array}{l}\text { Undefined } \\
\text { pedestrian } \\
\text { domain }\end{array}$} & Pearson & $.240^{* *}$ & .058 & .052 & -.021 & $.392^{* *}$ & 1 & & \\
\hline & Correlation & & & & & & & & \\
\hline & $\begin{array}{l}\text { Sig. } \\
\text { tailed })\end{array}$ & .000 & .234 & .289 & .662 & .000 & & & \\
\hline & $\mathrm{N}$ & 419 & 419 & 419 & 419 & 419 & 419 & & \\
\hline \multirow[t]{3}{*}{$\begin{array}{l}\text { People on } \\
\text { carriageway }\end{array}$} & $\begin{array}{l}\text { Pearson } \\
\text { Correlation }\end{array}$ & $.453^{* *}$ & $.317^{* *}$ & $.285^{* *}$ & $.126^{* *}$ & $.367^{* *}$ & $.247^{* *}$ & 1 & \\
\hline & $\begin{array}{l}\text { Sig. } \\
\text { tailed) }\end{array}$ & .000 & .000 & .000 & .010 & .000 & .000 & & \\
\hline & $\mathrm{N}$ & 419 & 419 & 419 & 419 & 419 & 419 & 419 & \\
\hline \multirow[t]{3}{*}{ Integration } & Pearson & $.182^{* *}$ & $.126^{* *}$ & $.258^{* *}$ & $.102^{*}$ & -.072 & $-.201^{* *}$ & $.258^{* *}$ & 1 \\
\hline & $\begin{array}{l}\text { Correlation } \\
\text { Sig. } \\
\text { tailed) }\end{array}$ & .000 & .010 & .000 & .036 & .139 & .000 & .000 & \\
\hline & $\mathrm{N}$ & 419 & 419 & 419 & 419 & 419 & 419 & 419 & 419 \\
\hline
\end{tabular}

\subsection{Key Findings}

This research complements pedestrian-vehicular conflict as "pedestrian contact with a potentially harmful vehicular traffic", following Hyden (1987) and Raford and Ragland (2003). This research is distinctive from the other research in the pedestrian safety arena taking conflict risks, rather than accident or crash data. This study best demonstrates the utility of this phenomenon, Planners may, thereby, play an important role in designing the locations where accidents will be happening, while precautions to be continued to eliminate the treat locations with accidents.

This study identifies seven built environment related microvariables and pedestrian volume. This supports the views of some researchers (for examples, Parks and Schofer 2006; Clifton and Kreamer-Fults 2007; Dumbaugh and Li 2010) to examine the relationship between risk of crashes and the social and physical environment where the conflict risks exist.

Moreover, a prototype method developed in this study can be incorporated to study any context, and can be valuable for preventing crashes at individual sites. The previous studies confine to site-specific studies, when only the nature of the conflict can differ according to the specific environmental characteristics.

Finally, this research develops a pre-determined coding scheme, taking photographs at equal distance units and undertaking a pedestrian perception survey to validate the results. The coding scheme, distance intervals and time periods that need to take the photographs and format of perception survey will be decided by any investigator who will use this method based on the research context. Thus, this offers much needed insight for having an objective rating system (Parks and Schofer 2006).

\section{Conclusion}

This research conceptualised the pedestrian-vehicular conflict phenomenon as it facilitates urban planners' and designers' analysis of the spatial circumstance with micro-variables of the built environment and propose planning and design interventions. Most of the research has conceptualised pedestrian-vehicular conflict through the accident records. However, there are causes for road accidents for which the absence of accurate data and lack of a specific method to analyse the causes posed a constraint to conducting research in this field.

Due to this conceptualisation, micro-level and primary data had to be gathered from a case study undertaken in the Kandy Heritage City, where automobiles, roads and car culture have contributed intensely to restructuring the urban built environment. Another reason that prompted the collection of this primary data is the uniqueness of the case study. Almost all the urban areas manifest unique characteristics in some respect, and problems with which planners need to deal are specific. Thus, an inductive research method is vital for framing the problems embedded in those cities. It is necessary to direct attention to historic cities, as the tailor-made solutions are too difficult to enforce due to their conservation and collective values.

A major challenge that we came across in this research field is the limitation of data and information to study the built environmental factors. In this context, a photographic survey was considered an ideal data collection method as it provides impartial, inexpensive, up-to-date information. The method provided in this study to record the empirical data is unique to this research arena, and it is widely applicable. At the same time, though the QGIS platform is not widely used for spatial analysis, this research illustrates that it is a convenient platform for geocoding, preparing maps and, most importantly, conducting space syntax analysis. Analysis with space syntax is new to this research area. Even though accurate pedestrian volume data are compulsory for this nature of research, utilisation of pedestrian counts is costly, and it is hard to find an 
up-to-date dataset. The space syntax modelling approach has been utilised to fill this gap with minimal additional input. It is less complicated and provides impartial outcomes. At the same time, this method enables the conversion of the qualitative data into quantitative data and the conduction of further statistical analysis.

The findings of the research are, first, the conceptualisation with definition and a criterion to identify built environmental causal factors that are particular to a case study. Though these findings are contextual, the authors believe that the concept of pedestrian-vehicular conflict and the methodology developed to identify causal factors in this research can be tailored to other towns. Second, the methodology indicates the possibility of doing spatial estimation in relation to pedestrian movement and the causal spots/locations. The construct validation also confirmed that some causal factors (four out of seven in this case) are appropriate for predicting the conflict, while the pedestrians' perception survey confirmed that the derived results are authentic (more than $80 \%$ ).

Although the results of the study add a strong base for understanding the given phenomenon, there exist some limitations in data recording and interpretations. It is necessary to generate axial lines manually to make the space syntax map and compute spatial integration. Though there is axial generation software, the lines have to be drawn manually, as the software is not compatible with QGIS. Xia (2013) states that manual axial maps may differ from person to person. Thus, there were some technical limitations involved in this research. The limitation of using space syntax is that it may lead us to underestimate the variation of land uses and under-predict the underground and above-ground pedestrian infrastructure networks.

Though photography was considered as the main source of data, it inherits some weaknesses; first, it records only the function of a particular point in time as a static image, and it is difficult to record the functional system of the space of that particular time; second, the capturing of the event as well as interpretation of the photographs can be subjective to some extent. Nonetheless, author tried to overcome these weaknesses by validating the findings with the pedestrian's perception survey and content analysis of the photographs by using a pre-determined coding scheme. Though the pedestrians' perceptions have been taken into consideration to minimise the imprecision by following the other research studies, this study could have benefited from following a time series photographic analysis to figure out outcomes that are more reliable. It is also important to point out that content analysis of photographs is time-consuming, and their application to a city of a larger scale could be a discouraging task. This research could have been impartially and speedily done had there been software to conduct content analysis of photographs. Thus, further research is necessary to explore a software for more convenient computer-based analysis.

If the planners and designers interested in studying pedestrianvehicular conflict prefer to microscopically experiment the real ground situation in order to explore applicable solutions, it is left to them to adopt this tested methodology.

\section{Reference}

Acock, A. C. (2008). A Gentle Introduction to Stata ( $2^{\text {nd }}$ ed.). College Station, Texas. Stata Press (USA).

Anderson, T. (2007). Comparison Of Spatial Methods For Measuring Road Accident 'Hotspots': A Case Study of London. Journal of Maps. 3(1): 55-63.

Bandara, A., Meetiyagoda, L. and Munasinghe, J. (2009). Spatial Configuration As A Determinant Of The Activity Pattern: The Case Of Two Small Cities In Sri Lanka. Bhumi. The Planning Research Journal. 2(2): $25-40$

Bandara, A., and Munasinghe, J. (2007). Evolution of a City: A Space Syntax Approach To Explain The Spatial Dynamics of Colombo. In Proceeding (s) of 9th International Congress of Asian Planning Schools Congress.

Ben-Joseph, E. (1995) Changing the Residential Street Scene: Adapting The Shared Street (Woonerf) Concept To The Suburban Environment. Journal of the American Planning Association. 61(4): 504-515.

Braddock, M., Lapidus, G., Cromley, E., Cromley, R., Burke, G. and Banco, L. (1994). Using a Geographic Information System To Understand Child Pedestrian Injury. American Journal of Public Health. 84(7):1158-1161.

Baran, P.K., Rodríguez, D.A. and Khattak, A.J. (2008). Space Syntax And Walking In A New Urbanist And Suburban Neighbourhoods. Journal of Urban Design. 13(1): 5-28.

Bernard, H.R., Wutich, A. and Ryan, G.W. (2016). Analyzing Qualitative Data: Systematic Approaches. SAGE publications.

Black, J. A., and Westerman, H.L. (1989). Pedestrian/Vehicle Conflict in The Main Street Of Country Towns. University of New South Wales Press (Australia).

Brison, R.J., Wicklund, K. and Mueller, B.A. (1988). Fatal Pedestrian Injuries To Young Children: A Different Pattern Of Injury. American Journal of Public Health. 78(7): 793-795.

Bunn, F., Collier, T., Frost, C., Ker, K., Steinbach, R., Roberts, I. and Wentz, R. (2003). Area-Wide Traffic Calming For Preventing Traffic Related Injuries. The Cochrane Library.

Chainey, S., Tompson, L. and Uhlig, S. (2008). The Utility Of Hotspot Mapping For Predicting Spatial Patterns Of Crime. Security Journal. 21(1-2): 4-28.

Clifton, K.J., Burnier, C.V. and Akar, G. (2009). Severity Of Injury Resulting From Pedestrian-Vehicle Crashes: What Can We Learn From Examining The Built Environment?. Transportation Research Part D: Transport and Environment 14(6): 425-436.

Clifton, K.J. and Kreamer-Fults, K. (2007) An Examination Of The Environmental Attributes Associated With Pedestrian-Vehicular Crashes Near Public Schools. Accident Analysis \& Prevention. 39(4): 708715 
Cloutier, M., Lachapelle, U., d'Amours-Ouellet, A., Bergeron, J., Lord, S. and Torres, J. (2017). "Outta My Way!" Individual And Environmental Correlates Of Interactions Between Pedestrians And Vehicles During Street Crossings. Accident Analysis \& Prevention. 104: 3645.

Crampton, J.W. (2002). Interactivity Types In Geographic Visualization. Cartography and Geographic Information Science. 29(2): 8598.

Dai, D., Taquechel, E., Steward, J. and Strasser, S. (2010). The Impact Of Built Environment On Pedestrian Crashes And The Identification Of Crash Clusters On An Urban University Campus. Western Journal of Emergency Medicine. 11 (3): 294

DiMaggio, C. and Li, G. (2011). Roadway Characteristics And Paediatric Pedestrian Injury. Epidemiologic Reviews. 34(1): 46-56.

Donroe, J., Tincopa, M., Gilman, R.H., Brugge, D. and Moore, D.A.J. (2008). Pedestrian Road Traffic Injuries In Urban Peruvian Children And Adolescents: Case Control Analyses Of Personal And Environmental Risk Factors. PLoS One. 3(9): 3166.

Dumbaugh, E. and Li, W. (2010), "Designing for the Safety Of Pedestrians, Cyclists, And Motorists In Urban Environments", Journal of the American Planning Association. 77(1):69-88

Eluru, N., Bhat, C.R. and Hensher, D.A. (2008). A Mixed Generalized Ordered Response Model For Examining Pedestrian And Bicyclist Injury Severity Level In Traffic Crashes. Accident Analysis \& Prevention. 40(3): 1033-1054.

Ewing, R., Handy, S., Brownson, R.C., Clemente, O. and Winston, E. (2006). Identifying and Measuring Urban Design Qualities Related To Walkability. Journal of Physical Activity and Health. 3(s1): S223-S240.

Gallin, N. (2001). Quantifying Pedestrian Friendliness--Guidelines For Assessing Pedestrian Level Of Service. Road \& Transport Research. 10(1): 47.

Gerring, J. (2004). What is a case study and what is it good for? American Political Science Review 98(2): 341-354.

Gil, J., Varoudis, T., Karimi, K. and Penn, A. (2015). The Space Syntax Toolkit: Integrating Depthmapx And Exploratory Spatial Analysis Workflows in QGIS. In SSS 2015-10th International Space Syntax Symposium, 10. Space Syntax Laboratory, The Bartlett School of Architecture, UCL (University College London).

Hajdu, J. C. (1988). Pedestrian malls in West Germany: Perceptions of Their Role And Stages In Their Development. Journal of the American Planning Association. 54(3): 325-335.

Hamilton-Baillie, B. (2008). Shared Space: Reconciling People, Places And Traffic. Built Environment. 34(2):161-181.

Hsieh, H. and Shannon, S.E. (2005). Three Approaches To Qualitative Content Analysis. Qualitative Health Research. 15(9): 1277-1288.

Hydén, C. (1987). The Development Of A Method For Traffic Safety Evaluation: The Swedish Traffic Conflicts Technique. Bulletin Lund Institute of Technology, Department 70.
Jiang, B. and Claramunt, C. (2002). Integration of Space Syntax Into GIS: New Perspectives For Urban Morphology. Transactions in GIS. 6(3): 295-309.

Kadali, B.R., Rathi, N. and Perumal, V. (2014). Evaluation of Pedestrian Mid-Block Road Crossing Behaviour Using Artificial Neural Network. Journal of Traffic and Transportation Engineering (English edition). 1(2): 111-119.

Khan, T.H., Isah, A.D., Anjomshoaa, E. and Sabri, S. (2015) Users' Perceptions On Pedestrian Prioritized Neighborhoods: A Study On Terrace Row Housing Estates in Malaysia. International Journal of Built Environment and Sustainability 2(1): 29-38

Khder, H.M., Mousavi, S.M. and Khan, T.H. (2016) Impact of Street's Physical Elements On Walkability: A Case Of Mawlawi Street in Sulaymaniyah, Iraq. International Journal of Built Environment and Sustainability. 3(1): 18-26

Kim, Y.O. and Penn, A. (2004). Linking the Spatial Syntax Of Cognitive Maps To The Spatial Syntax Of The Environment. Environment and Behavior. 36(4): 483-504.

McMahon, P.J. (2002). An Analysis Of Factors Contributing To" Walking Along Roadway" Crashes: Research Study And Guidelines For Sidewalks And Walkways. 1. DIANE Publishing.

Meetiyagoda, L. (2018). Pedestrian safety in Kandy Heritage City, Sri Lanka: Lessons from World Heritage Cities. Sustainable Cities and Society 38: 301-308

Meetiyagoda, L. and Munasinghe, J. (2016). Towards Great Streets: An Empirical Approach To Study A Streetscape. Bhumi. the Planning Research Journal 1(2): 34-49

Moudon, A., Lin, L., Hurvitz, L. and Reeves, P. (2008). Risk of Pedestrian Collision Occurrence: Case Control Study Of Collision Locations On State Routes in King County and Seattle, Washington. Transportation Research Record: Journal of the Transportation Research Board. 2073: 25-38.

Lerman, Y., Rofè, Y. and Omer, I. (2014). Using Space Syntax To Model Pedestrian Movement In Urban Transportation Planning. Geographical Analysis. 46(4):392-410.

Omer, I. and Kaplan, N. (2017). Using Space Syntax And Agent-Based Approaches For Modeling Pedestrian Volume At The Urban Scale. Computers, Environment and Urban Systems. 64:57-67.

Osama, A. and Sayed, T. (2017). Macro-Spatial Approach For Evaluating The Impact Of Socio-Economics, Land Use, Built Environment, And Road Facility On Pedestrian Safety. Canadian Journal of Civil Engineering. 44(12): 1036-1044.

Ossenbruggen, P.J., Pendharkar, J. and Ivan, J. (2001). Roadway safety in rural and small urbanized areas. Accident Analysis \& Prevention. 33(4): 485-498

Parks, J.R. and Schofer, J.L. (2006). Characterizing Neighbourhood Pedestrian Environments With Secondary Data. Transportation Research Part D: Transport and Environment. 11(4): 250-263. 
Penn, A. (2003). Space syntax And Spatial Cognition: Or Why The Axial Line?. Environment and Behaviour. 35(1): 30-65.

Perera, L.A.S.R. and Amin, A.T.M.N. (1996). Accommodating the Informal Sector: A Strategy For Urban Environmental Management. Journal of Environmental Management. 46(1): 3-15.

Pulugurtha, S.S., Krishnakumar, V.K. and Nambisan, S.S. (2007). New Methods To Identify And Rank High Pedestrian Crash Zones: An Illustration. Accident Analysis \& Prevention. 39(4): 800-811.

Raford, N. and Ragland, D.R. (2003). Space Syntax: An Innovative Pedestrian Volume Modeling Tool For Pedestrian Safety, Institute Of Transportation Studies. UC Berkeley Traffic Safety Center, UC Berkeley Google Scholar

Rahaman, K.B., Ohmori, N. and Harata, N. (2005). Evaluation of the Roadside Walkway Environment of Dhaka City. In Proceeding of the Eastern Asia Society for Transportation Studies. 5:1751-1766.

Ranasinghe, G., Amarawickrama, S., Rathnayake, R., Randeniya, T., and Rathnasiri, S. (2015). A Model For Assessing The Level Of Walkability In Urban Neighborhoods in Sri Lanka. International Journal of Built Environment and Sustainability. 2(4): 292-300

Robertson, K. A. (1993) Pedestrianization Strategies For Downtown Planners: Skywalks Versus Pedestrian Malls. Journal of the American Planning Association. 59(3): 361-370.

Rytkönen, M.J.P. (2004). Not All Maps Are Equal: GIS And Spatial Analysis In Epidemiology. International Journal of Circumpolar Health. 63(1): 9-24

Sarkar, S. and Andreas, M. (2004). Drivers' Perception Of Pedestrians' Rights And Walking Environments. Transportation Research Record: Journal of the Transportation Research Board. 1878: 75-82.

Schneider, R.J., Ryznar, R.M. and Khattak, A.J. (2004). An Accident Waiting To Happen: A Spatial Approach To Proactive Pedestrian Planning. Accident Analysis \& Prevention. 36(2):193-211.

Schuurman, N., Cinnamon, J., Crooks, V.A. and Hameed, S.M. (2009). Pedestrian Injury And The Built Environment: An Environmental Scan Of Hotspots. BMC Public Health. 9(1):233.

Sepe, M. (2009). PlaceMaker Method: Planning 'Walkability' By Mapping Place Identity. Journal of Urban Design. 14(4): 463-487.
Shepherd, M., Austin, P. and Chambers, J. (2010). Driveway Runover, The Influence Of The Built Environment: A Case Control Study. Journal of Paediatrics and Child Health. 46(12): 760-767.

Southworth, M. (2005). Designing the Walkable City. Journal of Urban Planning and Development. 131(4): 246-257.

Steenberghen, T.T., Dufays, I.T., and Flahaut, B. (2004). Intra-Urban Location And Clustering Of Road Accidents Using GIS: A Belgian Example. International Journal of Geographical Information Science. 18(2): 169-181.

Steinmetz, G. (2004). Odious Comparisons: Incommensurability, The Case Study, And "Small N's" In Sociology. Sociological Theory. 22(3): $371-400$.

Stoker, P., Adkins, A. and Ewing, R. (2017). Pedestrian Safety And Public Health. In Walking: Connecting Sustainable Transport with Health. 211-229.

Swanborn, P. (2010). Case Study Research: What, Why And How? Sage Publications

Tobler, W.R. (1973). Choropleth Maps Without Class Intervals?. Geographical Analysis. 5(3): 262-265.

Ukkusuri, S., Hasan, S. and Aziz, H. (2011). Random Parameter Model Used To Explain Effects Of Built-Environment Characteristics On Pedestrian Crash Frequency. Transportation Research Record: Journal of the Transportation Research Board. 2237: 98-106.

Wier, M., Weintraub, J., Humphreys, E.H., Seto, E. and Bhatia, R. (2009). An Area-Level Model Of Vehicle-Pedestrian Injury Collisions With Implications For Land Use And Transportation Planning. Accident Analysis \& Prevention. 41(1): 137-145.

Zaman, M., Sultan, Z., Fard, M., Siyaka, A. and Pung, J.C. (2017) An Assessment Of Public Transport Facility In Johor Bahru: A Case Study In Taman Ungku Tun Aminah Area, Majlis Perbandaran Johor Bahru Tengah, Malaysia. International Journal of Built Environment and Sustainability 4(2): 71-80

Zegeer, C.V. and Bushell, M. (2012). Pedestrian Crash Trends And Potential Countermeasures From Around The World. Accident Analysis \& Prevention. 44(1): 3-11. 